\title{
Multiple recurrent myxofibrosarcoma of the orbit: case report and review of the literature
}

\author{
Baixue $\mathrm{Du}^{1}$, Xin $\mathrm{He}^{2}$, Yujiao Wang ${ }^{1}$ and Weimin $\mathrm{He}^{1^{*}}$
}

\begin{abstract}
Background: Although myxofibrosarcoma (MFS) is the most common mesenchymal tumor, occurrence in the orbit is extremely rare. A characteristic clinical feature of MFS is its propensity for local recurrence (LR). Still, none of published literature has described the entire clinical course of multiple recurrences of MFS in the orbit. Here we present an unusual case in which a patient with multiple recurrences of MFS in the orbit followed-up for 5 years. We describe its clinical-pathological correlation, treatment, and prognosis.

Case presentation: A 70-year-old woman sought treatment for a year history of right upper eyelid swelling in May 2014. Since then, she underwent three surgical procedures in the right orbit in the same region (in 2014, 2016, and 2017). The pathology analysis of the three surgical tissue samples was consistent with myxofibrosarcoma, characterized by spindle-shaped cells and variably myxoid stroma. In the 2 years follow-up after the third surgery, there was no evidence of tumor recurrence.

Conclusion: Myxofibrosarcoma of the orbit is extremely rare. Since few reports are available in the literature, the diagnosis and management of the orbit myxofibrosarcoma is still a challenge to ophthalmologists. Histopathology is highly valuable in the diagnosis. As a clinical characteristic, the lesions have a high risk of local recurrence; therefore, aggressive resection and careful postoperative follow-up are paramount.
\end{abstract}

Keywords: Orbit, Multiple myxofibrosarcoma, Recurrent myxofibrosarcoma

\section{Background}

Myxofibrosarcoma (MFS) is the most common malignant soft tumor of the elderly, previously known as myxoid malignant fibrous histiocytoma (MFH) [1]. Since the new 2002 tumor classification system published by the World Health Organization (WHO), these tumors are considered as distinct pathological entities [2]. MFS usually appears in the body extremities, especially lower extremities, then trunk. Occurence in the orbit is extremely infrequent. In this

\footnotetext{
* Correspondence: hewm888@hotmail.com

'Department of Ophthalmology, West China Hospital of Sichuan University, No. 37 Guoxue Xiang, Wuhou District, Chengdu 610041, Sichuan Province, China

Full list of author information is available at the end of the article
}

article we describe a 70-year-old woman with a myxofibrosarcoma afflicting the orbit, presenting with multiple local recurrences.

\section{Case presentation}

A 70-year-old woman presented to our hospital with a one-year history of right upper eyelid swelling in May 2014. Her best-corrected visual acuities (BCVAs) were 0.6 in the right eye, 1.0 in the left eye. Binocular Intraocular pressure was normal. Physical examination revealed a palpable soft mass in the right upper eyelid with a size of $3 \mathrm{~cm} * 2 \mathrm{~cm}$. The exams of the right upper eyelid also presented with an increased volume. Complete resection of the tumor revealed a large oval encapsulated mass in close relation to the adjacent

(C) The Author(s). 2020 Open Access This article is licensed under a Creative Commons Attribution 4.0 International License, which permits use, sharing, adaptation, distribution and reproduction in any medium or format, as long as you give appropriate credit to the original author(s) and the source, provide a link to the Creative Commons licence, and indicate if changes were made. The images or other third party material in this article are included in the article's Creative Commons licence, unless indicated otherwise in a credit line to the material. If material is not included in the article's Creative Commons licence and your intended use is not permitted by statutory regulation or exceeds the permitted use, you will need to obtain permission directly from the copyright holder. To view a copy of this licence, visit http://creativecommons.org/licenses/by/4.0/ The Creative Commons Public Domain Dedication waiver (http://creativecommons.org/publicdomain/zero/1.0/) applies to the data made available in this article, unless otherwise stated in a credit line to the data. 
tissue. The histopathology examination revealed a spindle-cell tumor with a myxoid matrix, consistent with MFS. The Ki-67 proliferation index was $60 \%$.

Two years after the initial surgery, the patient was admitted to another hospital with a palpable mass at the same site and swollen right upper eyelid. She underwent surgery and pathological analysis confirmed the recurrence of MFS, with an invasion of the surrounding tissue. Immunohistochemical staining was negative for S-100, desmin, and positive for $\alpha$ SMA and for Ki67 in 20\% of nuclei. Unfortunately, no pathological section was available. Adjuvant radiation therapy was administered after surgery, but we were unable to collect information about the radiation therapy modalities.

One year after the second tumor resection, she returned to our hospital with progressive swelling of the right eyelid for nearly half a year. Ophthalmological examination showed visual acuity as $C F / 40 \mathrm{~cm}$ OD and 0.6 OS. The upper eyelid was swollen and ptotic. There was a $1.5 \mathrm{~cm}^{*} 1.5 \mathrm{~cm}$ palpable, firm, and movable mass in the inner part of the right upper eyelid (Fig. 1a). Slit lamp examination of the right eye showed a $6 \mathrm{~mm}^{*} 2 \mathrm{~mm}$ ulcer in the temporal cornea and a non-round pupil with extensive posterior synechiae and absent light reflex. The left eye examination revealed no abnormalities. Contrast-enhanced orbital CT showed a well-defined cystic to solid mass with a size of $1.9 \mathrm{~cm} * 1.9 \mathrm{~cm}$ in the superolateral part of the orbit, compressing the lateral eyeball (Fig. 1b). The patient underwent surgical tumor resection again revealing a lobulated shaped and firm mass with local necrosis (Fig. 1c). The final histological examination confirmed myxofibrosarcoma (MFS). On the microscopic examination it was visualized a nodular growth tumor with a prominent myxoid matrix (Fig. 2a). Another characteristic finding was the presence of prominent, elongated, curvilinear, thin-walled blood vessels (Fig. 2b). Immunohistochemical staining was positive for Vimentin (Fig. 3a), negative for desmin (Fig. 3b), S-100 (Fig. 3c), SMA and EMA. CD 34 was partially positive (Fig. 3d) and the proliferation marker Ki-67 positive rate was less than $1 \%$.
After the third surgery, the patient was followed-up for 2 years without tumor recurrence.

\section{Discussion and conclusions}

Myxofibrosarcoma (MFS) is the most common mesenchymal tumor in elderly patients, which, most of the time, presents as a painless, slowly-growing mass, with typical potential for local recurrence (LR). It is characterized by variably myxoid stroma with a distinct curvilinear vascular pattern.

MFS might develop in most parts of the body, but most commonly in the extremities, especially lower extremities, then the trunk. Orbital presentation of MFS is extraordinarily rare, and it was first described in 2008. Since then, only six cases have been published [3-8].

MFS has a high incidence of LR, ranging from 50 to $60 \%$. Some studies demonstrate locally recurrent MFS progressing to a higher-grade disease with an associated increase in metastatic potential $[9,10]$. However, none of these case series studies included orbital MFS. In the six published case reports featuring orbital MFS, the most extended follow-up period was 2 years, which cannot properly reflect relapsing or metastasis. One article has reported a case in which the patient underwent three surgeries as well [7]. Still, no pathological data was described regarding the former operations, making it hard to determine if it was a case of recurrent MFS. In our case we reported a 5 years follow-up after the initial surgery. The entire clinical course with two relapses can demonstrate the aggressive growth pattern of orbital MFS.

The diagnosis of MFS relies on the histopathology. Typically, the spindle-cells or stellate shaped cells populate in variably myxoid stroma and there are great differences in cellularity, polymorphism, and mitotic activity. A curvilinear vascular pattern can be remarkably found in most tumors [2, 11, 12]. Immunohistochemically, the tumor cells may show strong staining with vimentin and would be negative for Desmin, S-100, SMA [2, 11]. The histopathological differential diagnosis of MFS includes benign and

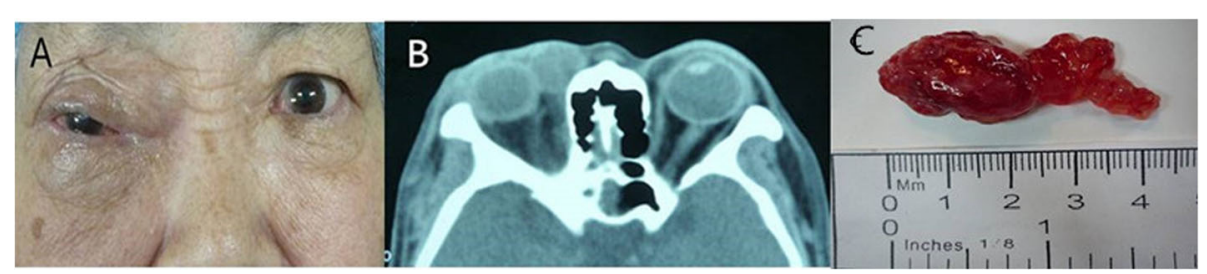

Fig. 1 a Photograph showing swelling and ptosis of the right eyelid. b Contrast-enhanced orbital CT showing a well-defined mass which compressed the lateral eyeball. c Gross appearance of the tumor showing a lobulated-shaped mass with local necrosis 


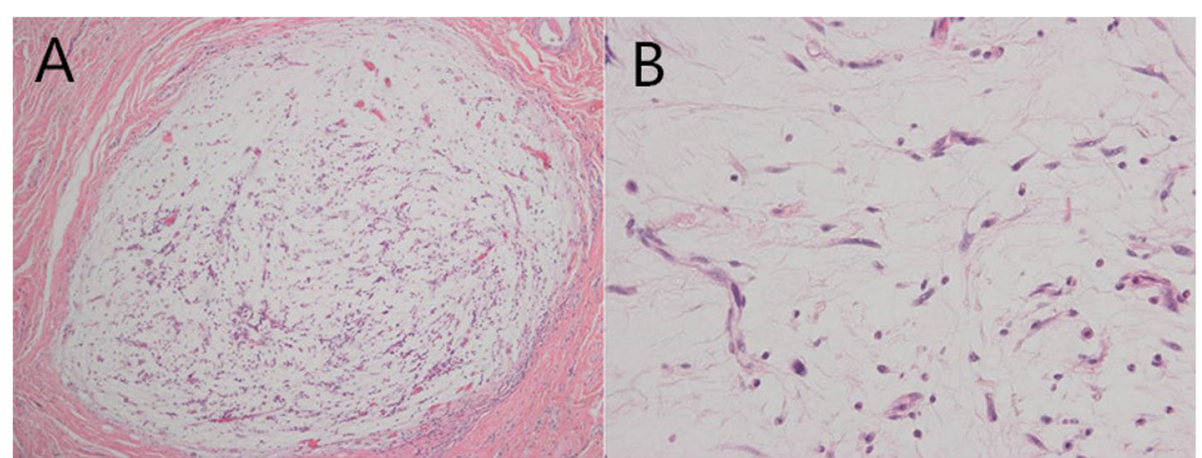

Fig. 2 a At low power, the tumor shows nodular growth with a prominent myxoid matrix (hematoxylin-eosin, $\times 100$ ). $\mathbf{b}$ At high power the tumor shows spindle-shaped cells and elongated, curvilinear, thin-walled blood vessels (hematoxylin-eosin, $\times 400$ )

malignant lesions. Benign lesions, such as nodular fascitis, myxoma, and spindle-cell lipoma, are all lack extensive vasculature. Malignant lesions include myxoid liposarcoma, pleomorphic dermal sarcoma, myxoid dermatofibrosarcoma protuberans, and lowgrade fibromyxoid sarcoma. One of the most difficult distinctions is the low-grade fibromyxoid sarcoma, which occurs mostly in young patients and is characterized by contrasting fibrous and myxoid areas, spindle-cells in a swirling and whorled pattern, with a variably myxoid $[1,13,14]$.
Since this kind of tumor is apt to recurrence and metastasis, margin-negative surgical resection is the most effective therapy. Insufficient tumor-free margins are associated with a high risk of local recurrence and, hence, a poor prognosis $[15,16]$. The role of radiation therapy and chemotherapy on the treatment of primary MFS remains uncertain. Nonetheless, some studies showed adjuvant radiation therapy providing the best local control [16-18]. In present case, although radiotherapy was used in second treatment, the period of recurrence is shorter than the surgery in

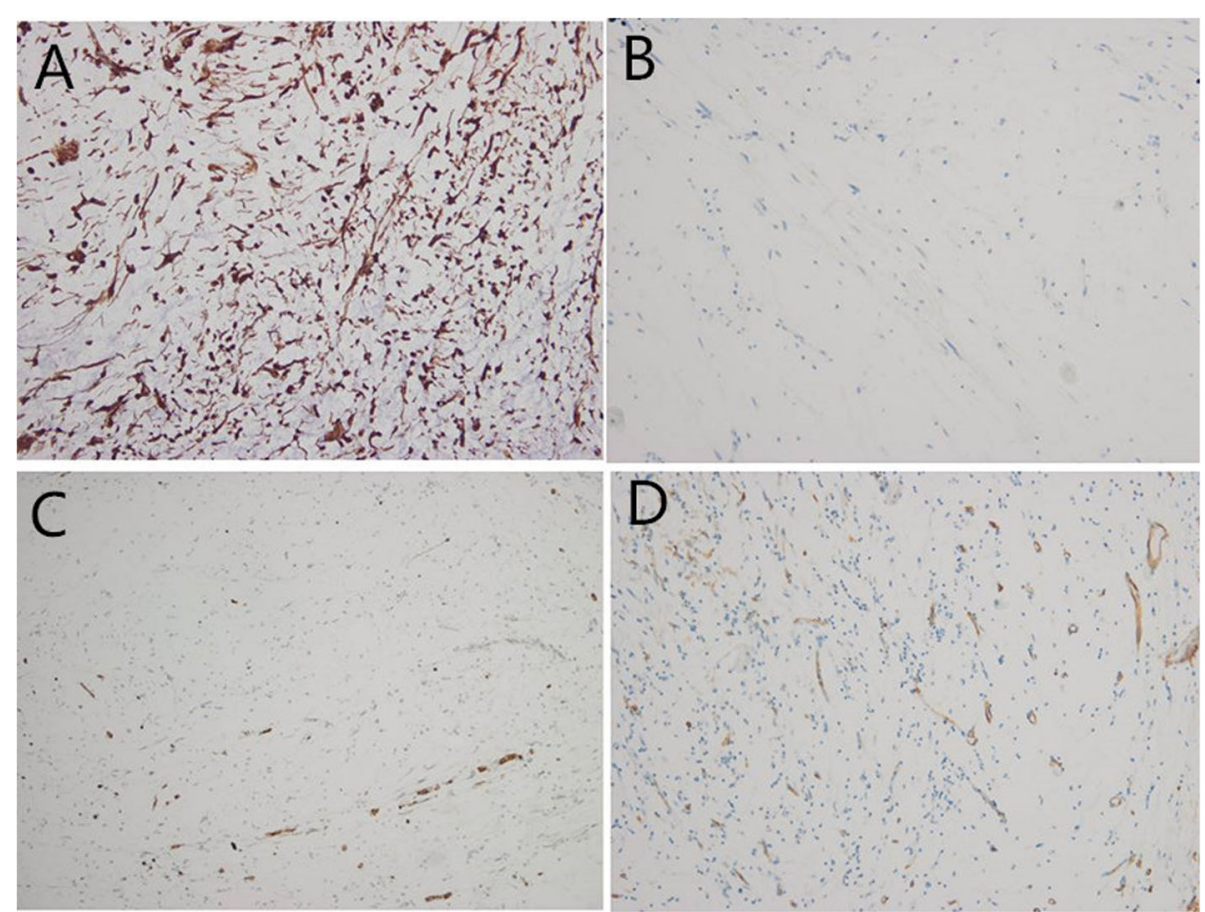

Fig. 3 Immunohistochemical analysis of the tumor tissue was positive for Vimentin (a) but negative for desmin (b) and S-100 (c). CD 34 was partially positive $(\mathbf{d})$ 
our hospital, maybe suggest that the adjuvant radiation therapy provide local control effectively limited.

Summarizing, primary MFS of the orbit is rare and can present a high recurrence rate. Our report described an entire clinical course of multiple recurrences of orbital MFS, reinforcing the importance of complete excision of these lesions. Ophthalmologists should be mindful of this diagnosis and closely monitor these patients.

\section{Abbreviations}

MFS: Myxofibrosarcoma; MFH: Myxoid malignant fibrous histiocytoma; BCVA: Best corrected visual acuity; LR: Local recurrence

\section{Acknowledgements}

Not applicable

\section{Authors' contributions}

BX was involved in the literature search, preparation and editing of the manuscript. XH was involved in collecting pathology data, interpretations of the pathological figures, revision and approval of the manuscript. YJ and WM were involved in the review and approval of the manuscript. All authors have read and approved the manuscript.

\section{Funding}

No funding was received by any of the authors for writing this manuscript.

\section{Availability of data and materials}

All data and supplementary information are included in this published article.

\section{Ethics approval and consent to participate}

Not applicable.

\section{Consent for publication}

Written informed consent for publication of the clinical details and accompanying images was obtained from the patient. A copy of the consent form is available for review by the editor of this journal.

\section{Competing interests}

The authors declare that they have no competing interests.

\section{Author details}

'Department of Ophthalmology, West China Hospital of Sichuan University, No. 37 Guoxue Xiang, Wuhou District, Chengdu 610041, Sichuan Province, China. ${ }^{2}$ Department of pathology, West China Hospital of Sichuan University, No. 37 Guoxue Xiang, Wuhou District, Chengdu 610041, Sichuan Province, China.

Received: 3 October 2019 Accepted: 30 April 2020

Published online: 06 July 2020

\section{References}

1. Weiss SW, Enzinger FM. Myxoid variant of malignant fibrous histiocytoma. Cancer. 1977:39(4):1672-85.

2. Fletcher CDM, UK, M F. Pathology and genetics of Tumours of soft tissue and bone. In: Kleihues P, Sobin LH, editors. World Health Organization classification of tumors. Lyon: IARC Press; 2002.

3. Wang M, Khurana RN, Parikh JG, et al. Myxofibrosarcoma of the orbit: an underrecognized entity? Case report and review of the literature. Ophthalmology. 2008;115(7):1237-40.

4. Zhang Q, Wojno TH, Yaffe BM, et al. Myxofibrosarcoma of the orbit: a clinicopathologic case report. Ophthalmic Plast Reconstr Surg. 2010;26(2): 129-31.

5. Gire J, Weinbreck N, Labrousse F, et al. Myxofibrosarcoma of the orbit : case report and review of literature. Ophthalmic Plast Reconstr Surg. 2012;28(1): e9-e11.
6. Pujari A, Ali MJ, Honavar SG, et al. Orbital myxofibrosarcoma : a clinicopathologic correlation of an extremely rare tumor. Ophthalmic Plast Reconstr Surg. 2014;30(5):e111-3.

7. Meel R, Lokdarshi G, Kashyap S, et al. Giant myxofibrosarcoma of the orbit: a rare case and a review of the literature. BMJ Case Rep. 2016;2016: r2015214107.

8. Clair BC, Salloum G, Carruth BP, et al. Orbital myxofibrosarcoma : case report and review of literature. Ophthalmic Plast Reconstr Surg. 2018;34(6):e180-2.

9. Angervall L, Kindblom LG, Merck C. Myxofibrosarcoma. A study of 30 cases. Acta Pathol Microbiol Scand A. 1977;85A(2):127-40.

10. Mentzel T, Calonje E, Wadden C, et al. Myxofibrosarcoma. Clinicopathologic analysis of 75 cases with emphasis on the low-grade variant. Am J Surg Pathol. 1996:20(4):391-405.

11. Goldblum JRM. Borderline and malignant fibroblastic/Myofibroblastic tumors. Enzinger Weiss Soft Tissue Tumors. 2014;Chapter 10:288-340.

12. Roland $\mathrm{CL}$, Wang W, Lazar AJ, et al. Myxofibrosarcoma. Surg Oncol Clin N Am. 2016;25(4):775-88.

13. Tjarks BJ, Ko JS, Billings SD. Myxofibrosarcoma of unusual sites. J Cutan Pathol. 2018;45(2):104-10.

14. HL E. Low-grade fibromyxoid sarcoma. A report of 12 cases. Am J Surg Pathol. 1993;17(6):595-600.

15. Song B, Lee $\mathrm{K}$, Lee $\mathrm{C}$, et al. Prognostic significance of microscopic tumor extension in local recurrence of myxofibrosarcoma and undifferentiated pleomorphic sarcoma. Pathol Int. 2018;68(9):509-16.

16. Boughzala-Bennadji R, Stoeckle E, Le Péchoux C, et al. Localized myxofibrosarcomas: roles of surgical margins and adjuvant radiation therapy. Int J Radiat Oncol Biol Phys. 2018;102(2):399-406.

17. Beane JD, Yang JC, White D, et al. Efficacy of adjuvant radiation therapy in the treatment of soft tissue sarcoma of the extremity: 20-year follow-up of a randomized prospective trial. Ann Surg Oncol. 2014;21(8):2484-9.

18. Mutter RW, Singer $S$, Zhang Z, et al. The enigma of myxofibrosarcoma of the extremity. Cancer. 2012;118(2):518-27.

\section{Publisher's Note}

Springer Nature remains neutral with regard to jurisdictional claims in published maps and institutional affiliations.

Ready to submit your research? Choose BMC and benefit from:

- fast, convenient online submission

- thorough peer review by experienced researchers in your field

- rapid publication on acceptance

- support for research data, including large and complex data types

- gold Open Access which fosters wider collaboration and increased citations

- maximum visibility for your research: over $100 \mathrm{M}$ website views per year

At BMC, research is always in progress.

Learn more biomedcentral.com/submissions 